\title{
UMA ANÁLISE DO PROGRAMA DE RECUPERAÇÃO DOS ALCOÓLICOS ANÔNIMOS
}

\author{
Bruno Alvarenga Ribeiro \\ Psicólogo especialista em Gestão de Pessoas e em Políticas de Assist. Social \\ Docente do Curso de Serviço Social do UNIFOR-MG \\ e-mail: br.alvarenga@yahoo.com.br \\ Gislaine Orício Dias Cunha \\ Graduada em Serviço Social pelo UNIFOR-MG \\ e-mail: gislaine_diascunha@yahoo.com.br \\ Lindamar Azarias \\ Graduada em Serviço Social pelo UNIFOR-MG \\ e-mail: lidamarazarias@hotmail.com
}

\begin{abstract}
RESUMO
Este artigo é uma versão resumida e modificada de um trabalho de conclusão de curso elaborado e defendido em 2010 como requisito para obtenção do título de bacharel em Serviço Social, trabalho que foi assim intitulado: "Alcoólicos Anônimos: um programa de reformulação de vidas". Ele tem como objetivo realizar uma análise dos 12 passos do programa de recuperação dos Alcoólicos Anônimos (AA). Para realização dessa análise, é utilizada a perspectiva teórica do Behaviorismo Radical. O Behaviorismo Radical é uma dentre as diversas teorias da Psicologia. Mas diferente de todas as outras, o Behaviorismo Radical não invoca a existência de faculdades mentais para explicar o comportamento. Para esta teoria psicológica o comportamento é uma relação estabelecida com meio social. Argumenta-se que o Behaviorismo Radical pode ser aplicado no entendimento de fenômenos sociais complexos, pois acredita-se que todo fenômeno social é antes de tudo um fenômeno comportamental.
\end{abstract}

Palavras-chave: Alcoólicos Anônimos. Os Doze Passos. Behaviorismo Radical.

\section{AN ANALYSIS OF THE PROGRAM FOR RECOVERING ALCOHOLICS ANONYMOUS}

\begin{abstract}
This article presents a modified and abridged version of a graduation dissertation of Serviço Social course. It's goal is to perform an analysis of the recovery program of Alcoholics Anonymous (AA). To perform thin proposed analysis, is used the theoretical perspective of Radical Behaviorism. Radical Behaviorism is one of several theories of psychology. But unlike all other theories of psychology, Radical Behaviorism does not allege the existence of mental mechanisms to explain the behavior. Radical Behaviorism believes that the causes of behavior are in the environment and the concept of environment also includes the social environment. It is argued that the Radical Behaviorism can be applied in understanding
\end{abstract}


complex social phenomena, because every social phenomenon is primarily a behavioral phenomenon.

Keywords: Alcoholics Anonymous. The Twelve Steps. Radical Behaviorism.

\section{INTRODUÇÃO}

A existência do problema do alcoolismo é notório na sociedade brasileira e ainda são raros os tratamentos no âmbito das ciências sociais usados no combate a este problema que sejam tão eficazes e de tão baixo custo como o modelo usado pelos Alcoólicos Anônimos (AA). Não existe na literatura dados comprobatórios sobre a eficácia do programa de recuperação proposto pelo AA, ou seja, sobre quantas pessoas se recuperam ou quantas pessoas recaem.

Todavia, num exercício intuitivo não é difícil imaginar o quão eficaz é o programa proposto pelos Alcoólicos Anônimos. O número de grupos do AA em todo mundo fornece uma estimativa sobre a capacidade da irmandade de se fazer presente em quase toda a superfície do globo terrestre. Segundo Reis (2007), no mundo atualmente existem 100.000 grupos do AA em 170 países e há aproximadamente um total de 2 milhões de membros. No Brasil, são aproximadamente 4.900 grupos de AA. Esses dados revelam com que facilidade o AA se faz presente em diferentes países, sendo capaz de se infiltrar em culturas as mais diversas.

Esta capacidade do AA de se infiltrar em uma diversidade de culturas é um dado mais do que suficiente para se intuir sobre a facilidade com o qual os seus princípios são aprendidos. Sendo facilmente aprendidos, estes princípios podem ser facilmente difundidos. Isso se torna um dado mais do que suficiente para se supor que é eficaz o programa de recuperação proposto pelo AA. Partindo do pressuposto que tal programa seja eficaz, torna-se relevante tomá-lo como objeto de uma análise científica, análise que pretende revelar o que existe nos princípios que fundamentam as atividades do AA e que fazem com que a irmandade dos Alcoólicos Anônimos seja tão conhecida.

Espera-se que a análise aqui apresentada possa contribuir para elucidar o que torna o grupo de AA um ambiente com uma atmosfera social favorável a mudança de comportamentos. E para que o intento possa ser atingido, os Doze Passos, conjunto de diretrizes que regem o funcionamento do programa de recuperação do AA, serão analisados a partir da perspectiva teórica do Behaviorismo Radical. 
O Behaviorismo Radical é uma das várias matrizes teóricas da Psicologia. Diferente de todas as outras, que tendem a entender o comportamento como um produto de mecanismos e instâncias mentais, o Behaviorismo Radical entende o comportamento como uma relação, uma relação que se estabelece entre o organismo que se comporta e o meio circundante, inclusive e principalmente o meio social. O Behaviorismo Radical é então a mais sociológica das abordagens teóricas em Psicologia.

Espera-se ainda, que ao se analisar o programa de recuperação do AA a partir da perspectiva teórica do Behaviorismo Radical, que seja possível demonstrar que tal teoria não necessita ficar circunscrita ao âmbito da Psicologia e pode ser utilizada por cientistas sociais na análise de fenômenos sociais complexos, afinal de contas, todo fenômeno social é antes de tudo um fenômeno comportamental, ou seja, todo fenômeno social é um produto da ação do Homem no mundo e ao mesmo tempo esta ação sofre os efeitos produzidos por suas consequências. Sendo assim, o fenômeno social é uma relação, uma relação do Homem com o mundo, relação que se efetiva pelo comportar-se. Portanto, o comportamento é o elo perdido para o entendimento de fenômenos sociais de pequena e grande escala, e a aplicação do Behaviorismo Radical à análise dos Doze Passos pode contribuir para corroborar tal tese.

Portanto, para efeito da discussão proposta o trabalho foi assim dividido. Na primeira parte serão apresentados os principais princípios teóricos do Behaviorismo Radical e a proposta de entendimento do comportamento a partir desta perspectiva teórica. Na segunda parte os Dozes Passos serão analisados a partir da perspectiva do Behaviorismo Radical.

\section{METODOLOGIA}

O objeto de estudos do presente ensaio são os 12 passos que constituem o programa de recuperação dos Alcoólicos Anônimos. O contato com estes passos se deu mediante a utilização do recurso da revisão bibliográfica. Assim foi possível conhecê-los, bem como entender a forma como são utilizados pelos grupos de Alcoólicos Anônimos. Em seguida estes passos foram analisados a partir da perspectiva teórica do Behaviorismo Radical. Pretendeu-se ao analisá-los demonstrar como contribuem para a produção de uma atmosfera social nos grupos do AA que criam ocasiões favoráveis a mudança de comportamentos.

Da mesma forma que ocorreu com os 12 passos, o contato com o Behaviorismo Radical também aconteceu mediante a utilização do recurso da revisão bibliográfica. Desta 
forma, foi possível proceder a um levantamento dos principais conceitos desta teoria, para em seguida aplicá-los na análise do programa de recuperação do AA. Privilegiou-se neste levantamento bibliográfico a obra de B. F. Skinner, criador do Behaviorismo Radical, e daqueles autores fiéis aos preceitos desta teoria.

\section{O BEHAVIORISMO: UMA INTRODUÇÃO}

O termo "Behaviorismo" vem do inglês "behavior". Behavior é equivalente a comportamento, então, behaviorismo seria o mesmo que comportamentalismo. Este termo foi usado inicialmente em 1913 pelo cientista norte americano chamado John Watson que criou a primeira proposta teórica chamada Behaviorismo na Psicologia. Depois da proposta original, muitos outros Behaviorismos surgiram, e o mais marcante de todos eles é o Behaviorismo Radical de B. F. Skinner (1904-1990), seja pela sua originalidade ou pela sua capacidade de utilizar o método experimental na análise do comportamento, sem que necessariamente tenham que ser excluídos do panorama de estudos da Psicologia os fenômenos subjetivos como ocorre em Watson. Em Skinner a subjetividade ganha uma formulação completamente original e compatível à utilização do método experimental na análise do comportamento. Original porque rompe com uma visão da subjetividade como palco de operações mentais e defende uma proposta em que eventos subjetivos não são sinônimos de eventos mentais. Isso será explorado mais adiante.

O Behaviorismo proposto por Watson ficou conhecido como "Behaviorismo Metodológico". Assim foi chamado por causa da excessiva ênfase dada por Watson ao papel da metodologia na produção de conhecimento científico. (MATOS, 1998). Tendo sido influenciado pelo positivismo, equacionou o fazer científico à produção de dados objetivos, e o que não fosse objetivo não poderia ser científico. Sendo assim, acabou por banir da Psicologia os fenômenos subjetivos, pois estes não poderiam ser observados e nem mensurados. Para Watson, o objeto de estudos da Psicologia é o comportamento observável, pois esse obedece aos critérios da observação e mensuração, critérios estabelecidos pelo positivismo como referência para se concluir o que pode ser considerado científico ou não. Então, em Watson, a mente não ganha lugar de destaque. Ela é excluída porque não pode ser observada e nem mensurada. Ela é somente excluída, não é negada. (MATOS, 1998).

Se o comportamento observável é o objeto de estudos da Psicologia, este, por sua vez, 
é causado pelo ambiente. Na proposta de Watson, os estímulos ambientais agem como aguilhões que atingem o organismo e provocam os diversos comportamentos. Por isso seu behaviorismo também ficou conhecido como o behaviorismo do estímulo-resposta. (MATOS, 1998). Mas o que é importante é que tanto os estímulos quanto os comportamentos por eles provocados atendem aos critérios de cientificidade do positivismo, pois são observáveis e mensuráveis. Atendo-se aos estímulos e comportamentos observáveis, Watson acreditava estar construindo um projeto de psicologia científica.

\section{BEHAVIORISMO RADICAL}

Diferente de Watson que equaciona o privado ao mental e por isso acaba excluindo da Psicologia os fenômenos subjetivos (MATOS, 1998), Skinner defende o estudo daquilo que chamou de eventos privados. Eventos privados são aqueles acessíveis somente à pessoa que se comporta. (BAUM, 1999). Skinner concorda com Watson quanto à definição do objeto de estudos da Psicologia: o comportamento, mas não limita sua proposta à análise dos comportamentos observáveis. Skinner admite o estudo dos eventos privados como pensamentos, emoções, sentimentos, imaginação, memória etc. Mas para ele eventos privados são sempre exemplos de eventos comportamentais. Então, emoção é comportamento, imaginação é comportamento, memória é comportamento etc. Todos esses eventos são exemplos de comportamentos que não são diretamente acessíveis, mas mesmo não sendo diretamente acessíveis continuam sendo comportamentos e por isso não podem ser ignorados como na proposta de Watson. Em última instância Skinner não ignora esses eventos por eles não serem observáveis, pois sua proposta de ciência é compatível com o estudo de fenômenos não acessíveis à observação direta.

No entanto, em Skinner, os eventos privados não são mentais. (MATOS, 1998). A única diferença entre os eventos privados e os comportamentos observáveis é a acessibilidade. Os eventos privados como os comportamentos observáveis possuem dimensões materiais e temporais, ou seja, ocupam um lugar no tempo e no espaço, por isso podem ser estudados com a utilização do método experimental. Mas todo evento privado foi um dia um evento público (observável), um evento aprendido a partir da ocorrência de certas circunstâncias públicas.

Skinner também defende que o comportamento é causado pelo ambiente. Mas, em 
Skinner, ambiente tem uma conotação muito mais ampla. Ambiente não é aquilo que é externo ao organismo, mas sim o que é externo ao comportar-se. (MATOS, 1999). Esta definição é suficientemente ampla para englobar os eventos privados.

O behaviorismo skinneriano defende radicalmente o modelo de causalidade ambientalista e rompe radicalmente com o modelo de causalidade mentalista, por isso ele é chamado de Behaviorismo Radical. (MATOS, 1998). Se para Watson a mente não era importante, para Skinner ela é uma invenção conceitual.

A grande contribuição de Skinner se deve à descoberta da classe de comportamentos que ele chamou de operante, pois há duas classes de comportamentos: respondentes (reflexos) e operantes. Os comportamentos reflexos são os comportamentos inatos, comportamentos que ocorrem sem a necessidade de aprendizagem prévia porque foram selecionados durante a evolução das espécies, devido ao seu valor de sobrevivência. (BAUM, 1999).

Os comportamentos operantes são aqueles que normalmente são chamados de voluntários. Não será discutida a voluntariedade do comportamento, pois no interior do Behaviorismo Radical ela ganha contornos bastante específicos. O Comportamento Operante é uma espécie de comportamento que engloba desde os mais simples gestos que fazemos ao nascer, até os mais elaborados como dirigir um carro ou pilotar um avião. O termo operante se refere ao fato de que essa classe de comportamento opera no meio modificando-o, e por sua vez essas modificações também alteram o comportamento, tornando-o o mais provável de ocorrer no futuro em condições semelhantes. Então, no condicionamento operante o comportamento é determinado (causado) pelas consequências que produz.

As consequências são tecnicamente chamadas estímulos reforçadores ou simplesmente reforços. Há estímulos reforçadores positivos e negativos. Reforço positivo é aquele estímulo que fortalece o comportamento quando acrescido à situação. Associados a eles estão os sentimentos de bem-estar, autoestima, realização, etc. Já o reforço negativo é aquele que fortalece o comportamento quando subtraído. Associados a este estão os sentimentos de tristeza, baixa autoestima, angústia, ansiedade etc. Se comportamentos podem ser fortalecidos pela apresentação de estímulos reforçadores, estes também podem ser enfraquecidos pela remoção destes mesmos estímulos. Quando há a remoção dos reforços que normalmente seguem determinado comportamento, este começa a enfraquecer e pode chegar ao ponto de desaparecer completamente. A esse processo dá-se o nome de extinção operante. Associado à extinção, estão os sentimentos de desmotivação ou de falta de perspectiva de vida, e isso 
acontece por causa da remoção dos reforços positivos, ou de alívio por causa da suspensão de estímulos reforçadores negativos.

Assim como existem duas operações de reforçamento (negativo e positivo), existem também dois tipos de reforços: incondicionados e condicionados. Estes podem assumir a função de reforços positivos ou negativos. Reforço incondicionado é todo reforço de importância biológica: comida, bebida, contato sexual, etc. Reforço condicionado é aquele estímulo que adquiriu a função de reforçador porque foi associado a um estímulo incondicionado. O dinheiro é um bom exemplo de reforço condicionado, pois com ele pode-se comprar bebida, comida, agasalhos etc.

Há uma outra operação comportamental que merece ser destacado por causa de seus efeitos. Essa operação é a punição. A punição diz respeito àquele procedimento comportamental, em que um comportamento é temporariamente suprimido por causa das consequências que produz. Estas consequências são chamadas de estímulos aversivos. Se o organismo pode terminar a ocorrência destes estímulos, o processo em operação é o de reforçamento negativo e não o de punição. Mas se os estímulos não podem ser terminados, fala-se, então, de punição. Outra distinção fundamental entre reforçamento e punição é que as operações de reforçamento produzem comportamento, já a punição suprime comportamento. A punição também pode se dar pela remoção de estímulos reforçadores positivos. Isso acontece, por exemplo, quando o pai ameaça tirar o vídeo-game do menino que não obedece às solicitações dos adultos. Todavia, a punição tem diversos efeitos emocionais colaterais nocivos. A longo prazo, ela funciona como desvantagem tanto para quem pune quanto para quem é punido. (SKINNER, 1998).

O comportamento operante não é controlado apenas pelas consequências que produz. Ele também é controlado pelas circunstâncias em que é emitido. Então, na determinação do comportamento operante, estão envolvidas as consequências (reforços ou estímulos reforçadores) e as condições antecedentes à ocorrência do comportamento (estímulos discriminativos). O comportamento sempre é reforçado dentro de certas circunstâncias e os estímulos que compõem estas circunstâncias se associam aos reforços, e por causa desta associação assumem o controle sobre o comportamento. Estes estímulos depois de associados aos reforços se tornam ao mesmo tempo reforçadores condicionados e estímulos discriminativos. Estímulos discriminativos são aqueles estímulos que sinalizam a possibilidade de apresentação de reforços. Outros estímulos parecidos com os estímulos 
discriminativos também são capazes de sinalizar a possibilidade de apresentação de reforços. A essa operação dá-se o nome de generalização de estímulos, e esta mostra, junto com a operação de estabelecimento de estímulos discriminativos, que são incontáveis os estímulos envolvidos na determinação do comportamento. Disso se conclui que o comportamento é um fenômeno complexo, porque são muitas as operações agindo ao mesmo tempo em sua ocorrência. Conclui-se também que a análise que o Behaviorismo Radical faz do comportamento considera a complexidade de tal fenômeno.

Então, contexto, comportamento e consequências formam o que tecnicamente é chamado de contingências de reforço. Contingência é um termo usado para designar a relação de dependência entre eventos ambientais e comportamentais. A relação entre comportamento e consequência é uma contingência, a relação entre comportamento e contexto é outra contingência e a relação entre contexto e consequências é também uma contingência. Tanto estímulos reforçadores quanto estímulos do contexto assumem com o comportamento uma relação de dependência, por isso são contingências. Analisar o comportamento é o mesmo que analisar essas relações de dependência, ou seja, corresponde a analisar as contingências de reforço. A seguir será proposta uma análise das contingências de reforço descritas nos dozes passos do AA.

Mas antes é importante salientar que este trabalho não pretende entrar no mérito da discussão sobre o alcoolismo ser ou não uma entidade patológica, e é bom assinalar que, de uma perspectiva behaviorista radical, não faz sentido tratar o alcoolismo como doença. Os problemas decorrentes do relacionamento com o álcool são problemas de comportamento, e para o Behaviorismo Radical todo comportamento é comportamento aprendido, até mesmo os comportamentos mais desajustados.

Para essa matriz teórica, as mudanças de comportamentos são um produto das alterações nas contingências de reforço responsáveis pela aquisição e manutenção do comportamento. Mesmo o AA tratando o alcoolismo como doença, seu programa de recuperação consegue criar contingências de reforço que favorecem tanto a mudança de comportamentos que geram problemas com a utilização do álcool, quanto a instalação de novos comportamentos que trazem ao alcoolista benefícios que anteriormente não eram alcançados. 


\section{OS DOZES PASSOS}

Deste ponto em diante será apresentada uma análise das contingências de reforço descritas nos dozes passos do AA, contingências que criam nos grupos de AA um clima social favorável às mudanças de comportamentos. Os passos foram retirados de JUNAAB, 1995.

1 Passo: “Admitimos que éramos impotentes perante o álcool - que tínhamos perdido o domínio sobre nossas vidas."

Admitir a impotência perante o álcool é admitir em alguma medida que o

comportamento de beber trouxe no passado consequências desastrosas. É sabido que o comportamento é determinado tanto pelas suas consequências, quanto pelo contexto em que ocorre.

Quando associados às consequências punitivas, os estímulos do contexto adquirem a função de estímulos aversivos. Tudo que lembra o álcool e os desastres a ele associados se tornam estímulos aversivos. Estes estímulos sinalizam que o álcool é um problema, ou melhor dizendo, que a ingestão do álcool é capaz de produzir consequências desastrosas as mais diversas. O alcoólico, admitindo que é impotente diante do álcool, está na verdade admitindo que reconhece as consequências punitivas que a ingestão do álcool é capaz de produzir e as circunstâncias que sinalizam estas consequências. Reconhecendo as circunstâncias, é capaz de evitá-las tão somente por terem se tornado aversivas. Neste sentido, se tornam aversivos vários estímulos: a garrafa, o bar, antigos amigos, lugares etc.

Vale dizer que o pareamento (a associação) entre os estímulos que sinalizam as consequências punitivas da ingestão do álcool e a ocorrência das mesmas é continuamente reforçado nas reuniões do AA. Nos depoimentos feitos nas reuniões os membros do AA contam suas experiências desastrosas com o uso do álcool. A cada depoimento mais se fortalece a conexão entre as punições geradas pela ingestão excessiva do álcool e as circunstâncias em que esta ingestão normalmente era feita. Cada vez mais, tudo que lembra o álcool se transforma em estímulos aversivos. Claramente opera no ritual dos depoimentos o princípio do reforçamento negativo.

Em outros passos, será possível perceber que o princípio do reforçamento negativo não é o princípio que predomina nos rituais do AA. Se fosse assim, o sistema de tratamento do AA tinha tudo para ser ineficiente. O princípio do reforçamento positivo é largamente 
utilizado e é ele que mantém muito provavelmente o comportamento de abstinência. Não mantém sozinho este comportamento, mas seus efeitos são inquestionáveis.

\section{$2^{\circ}$ Passo: "Viemos a acreditar que um poder superior a nós mesmos poderia} devolver-nos à sanidade."

O segundo passo leva o alcoólico a reconhecer a existência de um poder superior, a existência de um poder divino que é capaz de devolver-lhe a sobriedade. É um passo que sinaliza com esperança, que sinaliza que a recuperação é possível. Se esta ocorre por interferência de um poder divino não vem ao caso, e nenhuma análise científica seria capaz de prová-la. Todavia, uma análise científica pode revelar o que o comportamento de crer numa entidade divina proporciona ao membro do AA.

Ao acreditar num poder superior, o alcoólico está crendo que a recuperação é possível. Se antes o álcool estava associado ao completo descontrole, surge, então, no horizonte do membro do AA a possibilidade do controle, possibilidade produzida pelo comportamento de crer. É preciso aprofundar na análise aqui proposta. A ideia de Deus está associada à benevolência, caridade e por que não, sucesso e vitória. Essa ideia, como um estímulo discriminativo, sinaliza a possibilidade de sucesso e vitória no que se refere ao relacionamento com o álcool. Então há um forte componente motivacional no comportamento de crer em Deus.

Benevolência e caridade são duas experiências que praticamente inexistiam na vida do alcoólico quando no passado experimentou as mazelas da ingestão do álcool, mas com a entrada em um grupo de Alcoólicos Anônimos, estas experiências se tornam coisas reais. No Grupo do AA, os membros se tratam com respeito (benevolência e caridade), com isso, o alcoólico passa a ser exposto a novas contingências em que há uma superabundância de reforçamento positivo, diferente das contingências do passado em que havia uma superabundância de estímulos aversivos. Em última instância, acreditar na recuperação é uma ideia altamente reforçadora.

$3^{\circ}$ Passo: "Decidimos entregar nossa vontade e nossa vida aos cuidados de Deus, na forma em que $O$ concebíamos."

Entregar a vontade e a vida a Deus só aumenta as chances de obter aceitação de outros membros do AA. Se os outros membros creem nos passos de AA e, especialmente, creem no passo anterior e neste, o novo membro não tem outra alternativa a não ser acreditar também. Acreditando como os outros, o novo membro do AA aumenta as chances de ter seus 
comportamentos de abstinência reforçados pelos membros mais antigos. Neste passo, o membro de AA aumenta suas chances de vivenciar aquilo que a ideia de Deus sinaliza e que foi analisado no passo anterior.

\section{$4^{\circ}$ Passo: "Fizemos minucioso e destemido inventário moral de nós mesmos."}

No quarto passo, o membro de AA é estimulado a entrar em contato com as contingências que aumentavam a probabilidade do beber e com as consequências que o mesmo produziu num primeiro instante e num momento posterior. Ele passa a conhecer melhor os comportamentos que compõem o seu repertório de beber. Sendo assim, é capaz de reassumir o controle dos comportamentos que envolvem a ingestão de bebida alcoólica, tão somente porque pode manipular as contingências responsáveis pela determinação destes comportamentos.

Sabendo que antigas amizades e certos lugares são estímulos discriminativos que aumentam a probabilidade do beber, passa, então, a evitá-los. Este é um exemplo prático e simples de manipulação das contingências dos quais o comportamento de ingerir álcool é função. Ao fazer este inventário, o membro do AA também é levado a considerar a importância da ajuda dos outros, aumentando assim as chances de obtenção de reforços positivos. Contingências de reforçamento positivo vão produzir reações emocionais muito agradáveis comumente chamadas de autoestima elevada.

$5^{\circ}$ Passo: "Admitimos perante Deus, perante nós e perante outro ser humano, a natureza exata de nossas falhas."

Ao admitir suas falhas e dividi-las com o grupo, o membro do AA é reforçado por seus acertos. Mas a novidade é que ele não é punido por seus erros como era punido por familiares e pessoas próximas. Os comportamentos que geravam problemas não são punidos e nem são reforçados. Por não serem punidos, são evitadas as consequências do punir: raiva, frustração, medo, ansiedade etc.

A contingência a que o alcoólico estava anteriormente exposto era a seguinte: bebia e era punido por beber. A punição produzia seus efeitos emocionais nocivos. Para amortecer tais, efeitos o alcoólico voltava a beber. Ou seja, se encontrava preso em uma contingência de reforçamento negativo. O AA dá ao alcoólico a oportunidade de viver uma nova contingência. O membro não é punido pelos seus erros. Desta forma são evitados os efeitos colaterais da punição.

Mas o membro também não é reforçado por seus erros. Então, aos poucos os 
comportamentos que produziam os antigos problemas vão sendo colocados em extinção. No lugar dos antigos comportamento,s o AA vai modelando comportamentos mais funcionais (adequados), e a cada exibição destes novos comportamentos seguem-se os reforços positivos. Os efeitos emocionais resultantes das contingências de reforçamento positivo são comumente relatados como alegria, motivação, disposição, autoestima elevada etc.

$6^{\circ}$ Passo: "Prontificamo-nos inteiramente a deixar que Deus removesse todos esses defeitos de caráter."

Novamente, no sexto passo, o membro do AA é estimulado a vivenciar as experiências associadas à ideia de Deus. Aumentam-se as chances de se expor a contingências de reforçamento positivo e consequentemente de se sentir melhor consigo mesmo e com os outros.

\section{$7^{\circ}$ Passo: "Humildemente rogamos a Ele que nos livrasse de nossas imperfeições".}

O sétimo passo predispõe o membro do AA a aceitar a ajuda de um poder superior. Sentindo-se predisposto a aceitar a ajuda de alguém que não conhece, maior será a probabilidade do alcoólico a aceitar a ajuda daqueles que conhece. A ideia de Deus e de submissão a Ele cria uma contingência favorável à modelagem do comportamento de pedir e aceitar ajuda. Rogar pode ser entendido como pedir. Quem roga (pede) está disposto a aceitar ajuda. Aceitando, ajuda os laços entre os membros do AA se tornam mais sólidos. Essa experiência acaba se generalizando para outros âmbitos além do grupo do AA. Ou seja, os comportamentos de solidariedade que o membro do AA aprende quanto está exposto às contingências do grupo do AA, inevitavelmente, vão se mostrar úteis em outros contextos: família, trabalho, vida social etc.

A interpretação que os Alcoólicos Anônimos fazem do sétimo passo reforça a análise que dele está sendo feita: "é no Sétimo Passo que efetuamos a mudança em nossa atitude que nos permite, com a humildade servindo de guia, sair de dentro de nós mesmos em direção aos outros e a Deus." (JUNAAB, 1997, p. 68). Com a aceitação de ajuda, reforçam-se os laços entre os membros do AA, e tal experiência se generaliza para outros âmbitos da vida do alcoólico. Em outras palavras, ou com as palavras usualmente utilizadas no AA: com a aceitação de ajuda o membro de AA sai de si mesmo e vai ao encontro dos outros. Sair de si mesmo é estar disposto a se beneficiar das consequências produzidas pelo relacionamento estabelecido com outros que têm os mesmos problemas. $\mathrm{O}$ resultado é um potencial aumento de reforços positivos na vida do membro do AA, e os efeitos desses reforços é a modelagem 
de comportamentos úteis em outros âmbitos de sua vida.

$8^{\circ}$ Passo: "Fizemos uma relação de todas as pessoas a quem tínhamos prejudicado e nos dispusemos a reparar os danos a elas causados."

Se o sétimo passo havia criado uma contingência favorável à aproximação entre os membros do AA e destes com as pessoas de seu convívio, o oitavo potencializa os efeitos dessa contingência, pois estimula o alcoólico a reparar os danos causados aos seus relacionamentos quando da ingestão excessiva de álcool. Inevitavelmente, essa reparação eliminará muitas fontes de estímulos aversivos, e no lugar destes provavelmente vão surgir novas fontes de reforçamento positivo.

9' Passo: "Fizemos reparações diretas dos danos causados a tais pessoas, sempre que possível, salvo quando fazê-las significasse prejudicá-las ou a outrem."

$\mathrm{O}$ nono passo cria uma contingência que leva o membro de AA a analisar o comportamento de reparação de danos. Provavelmente ele gera indagações como: "Quais podem ser as consequências de tentar reparar os danos causados a esta e àquela pessoa?" "Estou pronto para lidar com essas consequências?" A análise das consequências leva a produção de comportamentos de cautela. Levam também o membro do AA a analisar quais circunstâncias são mais favoráveis à emissão do comportamento de reparação de danos. Analisando as circunstâncias haverá maior probabilidade de emitir o comportamento mais adequado em um momento mais favorável.

As circunstâncias são estímulos discriminativos que sinalizam a margem de sucesso que o membro do AA pode ter em sua empreitada de reparar os danos do passado. Então, este passo faz com que o membro do AA se torne consciente das circunstâncias e consequências que afetam o seu comportamento. Numa linguagem menos behaviorista e mais mentalista, o membro de AA tomou consciência de suas ações. Tomar consciência é nada mais nada menos do que ser capaz de descrever as variáveis que afetam o comportar-se neste ou naquele sentido. (SKINNER,1993). Descrevendo as circunstâncias (contexto e consequências) que afetam o comportar-se, é possível modificá-las de tal forma que o comportamento também irá se alterar.

10 Passo: "Continuamos fazendo o inventário pessoal e, quando estávamos errados, nós o admitimos prontamente."

O décimo passo potencializa as contingências arranjadas pelo quarto passo. Estas são retomadas e também os seus efeitos. Alargam-se as contingências de reforçamento positivo e 
minimizam-se os efeitos das contingências punitivas ou que sinalizam a possibilidade de punição. O efeito do alargamento das contingências de reforçamento positivo é claro: aumento das sensações relacionadas ao bem estar. Por causa disso, nesse momento o membro do AA estará mais disposto a dizer que sua autoestima está mais elevada. Com muita probabilidade ele relatará os efeitos emocionais das contingências de reforçamento positivo, dizendo que se sente mais feliz e seguro.

11 Passo: "Procuramos, através da prece e da meditação, melhorar nosso contato consciente com Deus, na forma em que $O$ concebíamos, rogando apenas o conhecimento de Sua vontade em relação a nós, e forças para realizar essa vontade."

A meditação aumenta o contado do membro do AA com seu repertório de comportamentos relacionados à ingestão e abstinência de álcool e com as circunstâncias que os afetam (contexto e consequências). Isso produz autoconhecimento. Conhecendo melhor as circunstâncias que afetam os seus comportamentos, o membro de AA pode ter mais controle sobre suas ações. O décimo primeiro passo produz autoconhecimento e autocontrole

12 Passo: "Tendo experimentado um despertar espiritual, graças a estes passos, procuramos transmitir esta mensagem aos alcoólicos e praticar estes princípios em todas as nossas atividades."

O décimo segundo passo estimula o membro de AA a reviver constantemente os passos anteriores. Com isso ele se expõe novamente às contingências arranjadas pelos onze primeiros passos. Esta exposição irá potencializar os efeitos destas contingências, produzindo comportamentos de abstinência e outros comportamentos que aumentarão a qualidade de vida do membro de AA. O décimo segundo passo também estimula o abstinente a transmitir os princípios de AA a outros. A transmissão destes princípios propiciará a criação de novas contingências de reforçamento positivo.

\section{CONCLUSÃO}

Ao se analisar os doze passos que constituem o programa de recuperação dos Alcooólicos Anônimos, percebeu-se que esses contribuem para a criação de uma atmosfera social que favorece a recuperação dos seus membros. Nesta análise feita a partir da perspectiva teórica do Behaviorismo Radical, ficou evidente que tal atmosfera é produto de contingências de reforço baseadas na utilização de reforçamento positivo. 
A minimização do controle aversivo e a maximização das contingências de reforçamento positivo contribuem para colocar em extinção os comportamentos relacionados à ingestão de bebidas alcoólicas e ao mesmo tempo permitem que novos comportamentos mais ajustados sejam modelados e instalados nos repertórios comportamentais dos membros do AA.

No entanto, essas experiências não se limitam ao grupo do AA. Elas acabam se expandindo para outros âmbitos da vida do alcoolista, inclusive para a sua vida social. Desta forma, novas contingências de reforçamento positivo vão sendo criadas, contribuindo assim para uma melhora no nível de qualidade de vida. Essas mesmas contingências são ainda responsáveis pela facilidade com que os princípios do AA são aprendidos e difundidos, o que em tese explicaria a presença dos grupos do AA em toda face do Globo Terrestre.

\section{REFERÊNCIAS}

AZARIAS, L.; CUNHA, G. O. D. Alcoólicos Anônimos: um programa de reformulação de vidas. 72 f. Trabalho de Conclusão de Curso (Graduação em Serviço Social)-Centro Universitário de Formiga-UNIFOR-MG, Formiga, 2010.

BAUM, W. M. Compreender o Behaviorismo: ciência, comportamento e cultura. Porto Alegre: Artes Médicas, 1999.

JUNTA DE SERVIÇOS GERAIS DE ALCOÓLICOS ANÔNIMOS DO BRASIL-JUNAAB. Os doze passos e as doze tradições. São Paulo, 1995.

MATOS, M. A. Behaviorismo metodológico e behaviorismo radical. In: RANGÉ, B. (Org.). Psicoterapia comportamental e cognitiva: pesquisa, prática, aplicações e problemas. 2. ed. Campinas: Editorial Psy, 1998. p. 27-34.

MATOS, M. A. Com o que o Behaviorismo radical trabalha? In: BANACO, R. A. (Org.). Sobre comportamento e cognição: aspectos teóricos, metodológicos e de formação em análise do comportamento e terapia cognitivista. 2. ed. Santo André: ARBytes, 1999. p. 4553.

REIS, T. R. Fazer em grupo o que eu não posso fazer sozinho: indivíduo, grupo e identidade social em Alcoólicos Anônimos. 2007. 468 f. Tese (Doutorado em Serviço Social)Universidade Federal do Rio de Janeiro, Rio de Janeiro, 2007.

SKINNER, B. F. Ciência e comportamento humano. 10. ed. São Paulo: Martins Fontes, 1998. 
SKINNER, B. F. Sobre o Behaviorismo. São Paulo: Cultrix, 1993. 